\title{
Optimization Design of Six Degrees of Freedom for Parallel Robot System
}

\author{
Yang $\mathrm{Na}$ \\ Mechanical and electrical technology department \\ Xijing University, \\ Shaanxi Xi'an ,China \\ e-mail: 515569778@qq.com
}

\begin{abstract}
The parallel robot of six degree of freedom is a kind of typical system for mechanical and electrical integration of liquid, and the great changes have taken place in the performance of the robot system by six degree of freedom. In this article, the introduction of six degrees of freedom of parallel robot is carried out; Six degrees of freedom parallel robot system is analyzed, the analysis includes the analysis of mechanical system, hydraulic system and control system analysis; Through the analysis of six degrees of freedom parallel robot system, the design of six degrees of freedom parallel robot system is optimized. It has important guiding significance for improving the performance of parallel robot system and promoting the development of parallel robot industry.
\end{abstract}

Keywords-Six degrees of freedom; Parallel robot; Mechanical system; Hydraulic system; Control system

\section{INTRODUCTION}

Mechanical and electrical integration technology is mechanical and electronic technology, microelectronics technology and the product of the mutual fusion each related technology. Mechanical and electrical integration of liquid as a kind of engineering machinery, mainly consists of sensor, transmission lines, MCU or microcomputer [1]. Mechanical and electrical integration of liquid makes great changes have taken place in the performance of the engineering machinery. Among them, the hydraulic drive system of parallel robot is a typical hydraulic and mechanical and electrical integration system. Parallel robot system has high rigidity, small inertia, large capacity, high speed, high precision, etc [2]. Parallel robot system has been widely used in aerospace, aviation, medical treatment, nc machining and micro control etc. In this paper, six degree of freedom parallel robot system as an example, to analyse the optimization design of the hydraulic and electromechanical integration system.

\section{INTRODUCTION OF SIX DEGREES OF FREEDOM PARALLEL ROBOT}

The composition mainly includes six degrees of freedom parallel robot platform, the platform and six branched chain. Among them, six branched chain is six interplanting actuator. Each actuator is electro-hydraulic servo drive system. Six degrees of freedom parallel mechanism of parallel robot has many advantages, such as compact structure, high rigidity, large carrying capacity; High speed, good dynamic response, etc. For the six degrees of freedom parallel robot, Stewart (6 - SPS) is the

\author{
Miao Shang \\ Mechanical and electrical technology department \\ Xijing University, \\ Shaanxi Xi'an ,China \\ e-mail:445700839@qq.com
}

most representative. Gough - Stewart platform mechanism schematic diagram is shown in Fig .1.

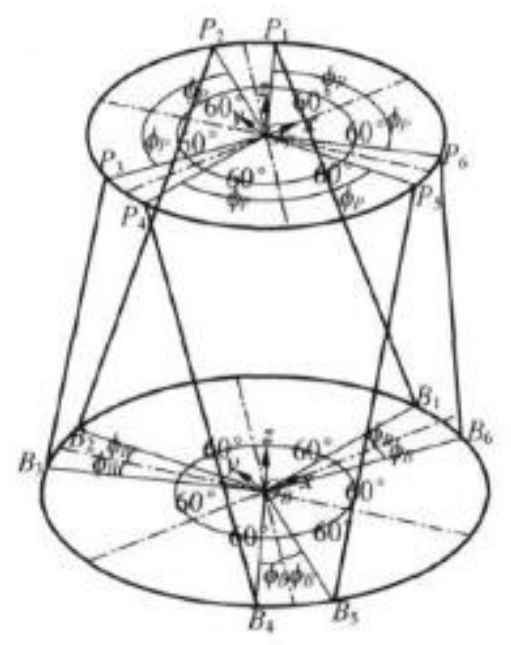

Figure 1. Platform schematic diagram of Gough - Stewart

Six degrees of freedom parallel robot system overall optimization design of the main is the overall design of the extraction of six degrees of freedom parallel robot system parameters, satisfying the multidisciplinary design optimization system in constraint conditions, to maximize the overall performance of the six degree of freedom parallel robot system of indicators [3].

\section{ANALYSIS OF six degrees of FREEDOM OF PARALLEL ROBOT SYSTEM}

Six degrees of freedom parallel robot system including mechanical system analysis and control system analysis.

\section{A. The analysis of mechanical system}

1) The location of the analysis

Due to the complexity of the structure of the parallel mechanism 'sex, the positive position solution difficulty is larger. In this paper, six degree of freedom parallel robot system design optimization using the inverse method.

In order to describe the movement of moving platform, set up two coordinate system, namely fixed coordinate system of the next platform $\{B, X, Y, Z\}$ and attached to the platform inertial system on $\{\mathrm{P}, \mathrm{X}, \mathrm{Y}, \mathrm{Z}\} .(\mathrm{X}, \mathrm{Y}, \mathrm{P})$ as the origin of the moving platform location in the fixed coordinate system (alpha, beta, gamma) as the origin of the moving platform azimuth in the fixed coordinate system. 
Relative to a fixed coordinate system of the first article I branched chain length of the vector is:

$$
\lambda \imath=\delta+P \pi \Pi \imath-\beta \imath, \imath=1,2, \square, 6
$$

In equation $1, \mathrm{~d}$ said the origin of the inertial coordinate system relative to a fixed coordinate system in the coordinates of the vector [4]. $\mathrm{P}_{\mathrm{i}}$ said hinge point on $\mathrm{Pi}$ $(\mathrm{I}=1,2, \ldots 6)$ relative to the inertial coordinate system the coordinates of the vector; $B_{i}$ says the hinge point $b_{i}(I=1$, $2, \ldots 6)$ relative to a fixed coordinate system the coordinates of the vector. Article I the branched chain elongation as follows:

$$
\geq \lambda_{l}=\left|\lambda_{l}\right|-\lambda_{l} 0
$$

In equation (2), article I the branched chain 1_i0 said initial length.

When determining the basic size system institutions and on the platform of the position and posture, is obtained by equation 2 can six actuator displacement [5].

\section{2) The analysis of dexterity}

In the study of parallel mechanism, the dexterity is commonly used as indicators to measure the motion accuracy of parallel robot. Therefore, this article USES the parallel robot dexterity to measure the motion accuracy of parallel robot.

Through the analysis, when the dexterity of value is 1 , the mechanism motion transmission performance of the best. If the condition number of Jacobian is very big, can the speed inverse solution of parallel mechanism, can lead to the input speed and output speed of the transitive relation between severe distortion, usually using dexterity as one of the most important indicators to measure the size of such movement distortion. In parallel robot mechanism design, the condition number of jacobian matrix in its kinematic range should be as small as possible.

\section{3) The analysis of dynamic}

For the mechanical system dynamics modeling are Lagrange (Langrange) method and Descartes, currently with the more is the Lagrange method [6]. Lagrange method is based on the energy of the mechanical system to establish the equation of motion, for any mechanical system, L Langrange function can be defined asthe difference between of the kinetic energy Pand potential energy $\mathrm{K}$.

\section{B. The analysis of hydraulic system}

Hydraulic system mainly include fuel tanks, hydraulic pump, all kinds of valve, hydraulic cylinder, piping and piping interface, etc. Hydraulic system of the control object is moving platform, the behavior of the controlled object is controlled by the hydraulic cylinder. In electrohydraulic drive hydraulic system, hydraulic cylinder under the control of the switch amplifier and power output required movement, transformation amplifier element includes throttle valve, electromagnetic directional valve and proportional direction valve, electro-hydraulic servo valve, servo variable pump, etc., it is the core of the fluid flow control and power transmission, the given signal receiving controller, and power amplification, converted into a hydraulic signal (flow, pressure). Power source is hydraulic pump, its role is to put the other forms of energy into hydraulic energy. The hydraulic cylinder with piston cylinders, hydraulic pump with constant pressure variable pump.

(1) Flow continuity equation of the hydraulic cylinder

Flow into the rodless hydraulic cylinder cavity flow is equal to the required flow rate, fluid compression piston movement flow and the sum of leakage. Flow continuity equation of the hydraulic cylinder is as follows:

$$
\begin{aligned}
& \mathrm{Q}_{1}=\mathrm{A}_{1} \frac{\mathrm{dx_{p }}}{\mathrm{dt}}+\mathrm{C}_{\mathrm{t}}\left(\mathrm{P}_{1}-\mathrm{P}_{2}\right)+\mathrm{CP}_{1}+\frac{\mathrm{V}_{1}}{\beta} \frac{\mathrm{dp_{1 }}}{\mathrm{d}_{\mathrm{t}}} \\
& \mathrm{Q}_{2}=\mathrm{A}_{2} \frac{\mathrm{dx_{p }}}{\mathrm{dt}}+\mathrm{C}_{\mathrm{t}}\left(\mathrm{P}_{1}-\mathrm{P}_{2}\right)+\mathrm{CP}_{2}+\frac{\mathrm{V}_{2}}{\beta} \frac{d p_{2}}{d_{\mathrm{t}}}
\end{aligned}
$$

In the equation (3) and equation (4), $\mathrm{Q}_{1}$ is the rodless cavity flow, $Q_{2}$ is rod cavity flow, effective area $A_{1}$ is no piston rod chamber work, $A_{2}$ is effective area of piston rod chamber work, the $\mathrm{Ce}$ is the external leakage coefficient of hydraulic cylinder, $\mathrm{V}_{1}$ and rodless hydraulic cylinder cavity and the volume sum of the servo valve connection management, $\mathrm{V}_{2}$ is hydraulic cylinder rod chamber and the volume sum of the servo valve connection management, beta is the volume of the hydraulic oil elastic modulus e, $\mathrm{P} 1$ is the rodless hydraulic cylinder cavity pressure, $\mathrm{p}_{2}$ is the pressure in the hydraulic cylinder rod, $x p$ is the displacement of hydraulic cylinder. Among them:

$$
\mathrm{A} 1=1 / 4 \square \bullet \Delta 2 \quad, \quad \mathrm{~A} 2=1 / 4 \square \bullet(\Delta 2-\delta 2)
$$

In the equation (5), $\mathrm{d}$ is the piston rod diameter , $\mathrm{D}$ is the piston diameter.

(2) The balance equation of load the force of the hydraulic cylinder

$$
A_{1} P_{s}+A_{2} P_{L}=M_{t} \frac{d^{2} x_{p}}{d t^{2}}+B_{p} \frac{d x_{p}}{d t}+F_{L}
$$

In equation (6), the ps for the system of oil supply pressure $(\mathrm{Pa}), \mathrm{pL}$ for load pressure difference $(\mathrm{Pa}), \mathrm{pL}=$ P1 P2

Mt for the quality of the equivalent load of the hydraulic cylinder $(\mathrm{kg}), \mathrm{BP}$, the total viscous damping coefficients for hydraulic cylinder ((Ns/m), all negative

Load disturbance force $(\mathrm{N})$.

(3) The flow equation of valve port for servo valve

$$
\mathrm{Q}_{\mathrm{L}}=\mathrm{K}_{\mathrm{q}} \mathrm{X}_{\mathrm{v}}-\mathrm{K}_{\mathrm{c}} \mathrm{P}_{\mathrm{t}}
$$

In equation (7), $x_{p}$ for the displacement of the slide valve $\mathrm{QL}$ for slide valve flow, $\mathrm{K}_{\mathrm{p}}$ to slide the total flow gain. Slide valve of the total flow pressure coefficient, $\mathrm{pl}$ for the pressure difference on both sides of the slide valve.

Slide valve total flow gain can be made of the following formula

$$
\mathrm{K}_{\mathrm{q}}=\frac{\partial \mathrm{Q}_{\mathrm{L}}}{\mathrm{X}_{\mathrm{V}}}=\mathrm{C}_{\mathrm{d}} \varepsilon \sqrt{\frac{\left(\mathrm{P}_{\left.\mathrm{s}-\mathrm{P}_{\mathrm{L}}\right)}\right.}{\rho}}
$$

Slide valve can use the following formula to calculate the total traffic pressure

$$
\mathrm{K}_{\mathrm{C}}=\frac{\partial \mathrm{Q}_{\mathrm{L}}}{\partial \mathrm{P}_{\mathrm{L}}}=\frac{\mathrm{C}_{\mathrm{d}} \mathrm{Wx}_{\mathrm{W}} \sqrt{\left(P_{\mathrm{s}}-P_{\mathrm{d}}\right.}}{2\left(\mathrm{P}_{\mathrm{s}}-P_{\mathrm{L}}\right)}
$$

(4) The hydraulic cylinder main dimensions 
For piston cylinder, cylinder and piston rod diameter D can choose according to the maximum total load and work pressure. For single rod cylinder (10), the rodless cylinder into liquid, regardless of the mechanical efficiency, the inner diameter of the cylinder D was got through the equation.

$$
\mathrm{D}=\sqrt{\frac{4 \mathrm{~F}_{1}}{\pi\left(\mathrm{P}_{1}-\mathrm{P}_{2}\right)}-\frac{\mathrm{d}}{\mathrm{P}_{1}}}
$$

When the hydraulic cylinder piston reciprocating faster than it has certain requirements, stem diameter $d$ as follows:

$$
\mathrm{d}=\mathrm{D} \sqrt{\frac{\varphi-1}{\varphi}}
$$

A cylinder wall thick $\delta$ :

$$
\delta=\frac{\mathrm{pD}}{2 \sigma}
$$

(5) The maximum flow of hydraulic cylinder

The hydraulic cylinder of $\mathrm{Q}_{\max }$ maximum flow rate is:

$$
\mathrm{Q}_{\max }=\mathrm{Av} v_{\max }
$$

In equation (13), A hydraulic cylinder for effective work area, V Max for hydraulic cylinder maximum speed.

\section{The analysis of control system}

Six degrees of freedom parallel robot system consists of six valve control hydraulic cylinder to drive the moving platform, because 6 set of servo hydraulic cylinder used in parallel manner, to drive the moving platform, each servo hydraulic cylinder must be coordinated movement, parallel robot system in the process of its motion will not produce the phenomenon of instability and. According to the parallel robot system to the different requirements of each servo hydraulic cylinder motion through displacement of servo hydraulic cylinder to control. Six degrees of freedom parallel robot control system is shown in figure 2 .

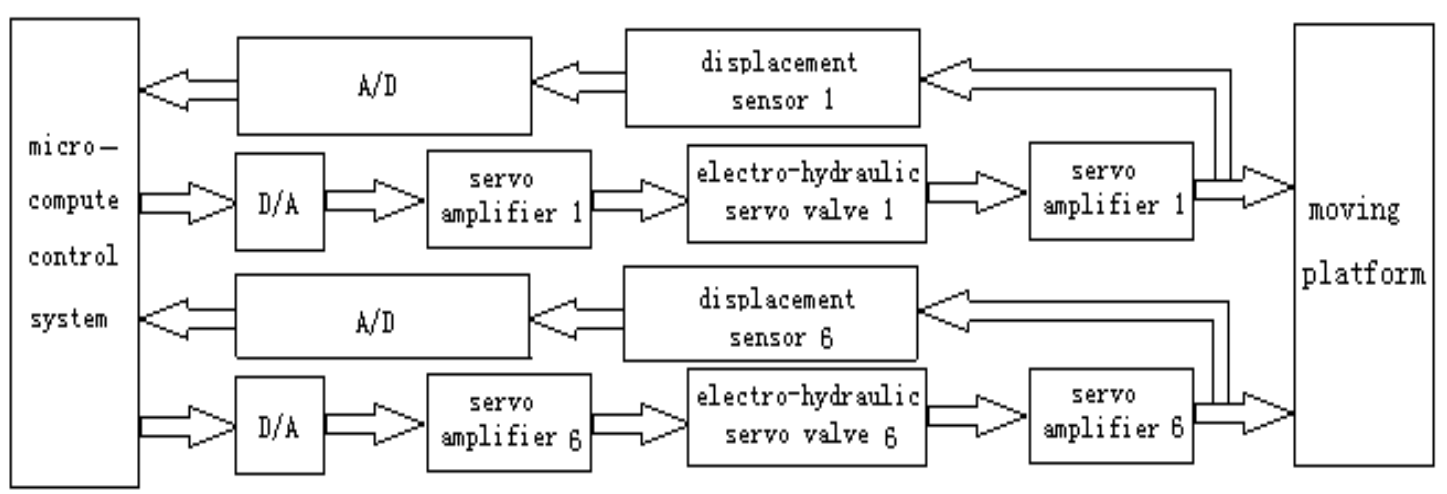

Figure 2 The control system of 6 dof parallel robot

According to the movement state of the parallel robot system by computer processing of each servo hydraulic cylinder displacement signal to control the motion of the robot, ensure the robot to a certain state of motion. Parallel robot's hydraulic drive control of the branched chain were independent of each other, and each of the branched chain structure and control system is composed of the same [7]. To accept the position feedback signal, the microcomputer control system and according to the signal and advance planning has been deposited in the moving location information in the computer, and provides the system as to the quantitative.

\section{1) The electronic hydraulic system}

This system electronic hydraulic system, the servo amplifier of the depth of the commonly used current servo amplifier [8], it has a lot of advantages of equivalent resistance and equivalent voltage amplification factor can inhibit the load coil resistance change on the influence of the output current, improve the control precision of the system [9]. The depth of the current general form of the transfer function is the servo amplifier

$$
\mathrm{I}(\mathrm{S}) / \mathrm{U}(\mathrm{S})=\mathrm{K}_{0} /\left(1+\mathrm{S} / \omega_{0}\right)
$$

In equation (14), I for the output current of the servo amplifier, $U$ is the output voltage of the servo amplifier,
Ka for servo amplifier gain, omega is a torque motor coil frequency.

Because omega is far greater than a natural frequency of the electro-hydraulic servo valve, inertial link above can be simplified into a proportion link:

$$
\mathrm{I}(\mathrm{S}) / \mathrm{U}(\mathrm{S})=K_{0}
$$

2) The flow servo valve of electric hydraulic

$$
G(S)=\frac{K_{5 v}}{2 \xi_{s v} / \omega_{s v}+S^{2} / \omega_{s v^{2}+1}}
$$

In equation (16), the $\mathrm{K}_{\mathrm{sv}}$ gain for the servo valve, deduced the sv for the damping ratio, average of $0.5-0.7$, omega sv for natural frequency [10].

$$
\text { 3) D/A converter }
$$

D/A converter can be abstracted as zero order retainer and amplification.

$$
\frac{\mathrm{U}(\mathrm{s})}{\mathrm{E}(\mathrm{S})}=\mathrm{K}_{\mathrm{DA}} \cdot \frac{1-\mathrm{e}^{\mathrm{TS}}}{\mathrm{S}}
$$


In equation (17), $\mathrm{K}_{\mathrm{DA}}$ for gain, $\mathrm{d} / \mathrm{a}$ converter for sampling period $\mathrm{T}$. When the system sample frequency $\mathrm{s}>$ $10 \mathrm{c}$ omega, omega can ignore the zero order retainer[11].

4) Hydraulic cylinder control mathematical model

Laplace transform of the above all kinds of simplified finishing after got from QL servo valve output flow to the transfer function of hydraulic cylinder displacement XP.

$$
G_{p}(S)=\frac{X_{P}(S)}{Q_{L}(S)}=\frac{1 / A_{D}}{S\left(\frac{S^{2}}{w_{h}{ }^{2}}+\frac{2 l_{h}}{\omega_{h}} S+1\right)}
$$

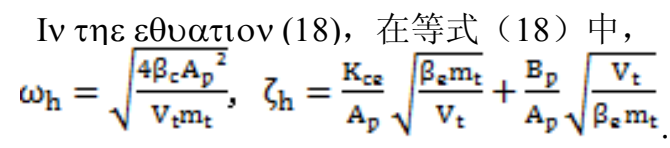

\section{5) Displacement sensor}

Displacement sensor can be regarded as a proportion.

$$
\mathrm{U}_{\mathrm{w}}=\mathrm{K}_{\mathrm{w}} \mathrm{\gamma}_{\mathrm{h}}
$$

In the equation (19), $\mathrm{Kw}$ for displacement sensor gain.

$$
\text { 6) Controller }
$$

When the PID controller, the transfer function can be expressed as:

$$
G_{c}(S)=K_{p}\left(1+\frac{K_{s}}{T_{1} S}+K_{D} S\right)
$$

In equation (20), for proportional coefficient $\mathrm{K}_{\mathrm{p}}, \mathrm{K}_{\mathrm{l}}$ for the integral time constant, $\mathrm{KD}$ for differential time constant.

\section{7) Control system block diagram}

In a single chain system model, the main dynamic element for the servo valve, hydraulic cylinder, for oil return pipe, sensor, controller and load, etc.

\section{CONCLUSIONS}

Parallel robot system has many advantages, such as high stiffness, small inertia, large capacity, high speed, high precision, etc. Parallel robot system has been widely used in aerospace, aviation, medical treatment, nc machining and micro control etc. In this article, the parallel robot of six degree of freedom is a kind of typical system for mechanical and electrical integration of liquid, and the great changes have taken place in the performance of the robot system by six degree of freedom. The introduction of six degrees of freedom of parallel robot is carried out; Six degrees of freedom parallel robot system is analyzed, the analysis includes the analysis of mechanical system, hydraulic system and control system analysis; Mechanical system is analyzed by the organization position, dexterity, dynamics; Hydraulic system is analyzed,and the analysis includes the flow continuity equation, load the force balance equation of the hydraulic cylinder, servo valve valve port flow equation, the hydraulic cylinder of main dimensions, the weight of the hydraulic cylinder, hydraulic cylinder, maximum flow rate; The control system is analyzed, the analysis includes electronic servo amplifier, electric hydraulic flow servo valve, D/A converter, the mathematical model of hydraulic cylinder controlled displacement sensor, controller and the control system block diagram. Through the analysis of six degrees of freedom parallel robot system, the design is optimized for six degrees of freedom parallel robot system.Through the analysis of six degrees of freedom parallel robot system, the design of six degrees of freedom parallel robot system is optimized. It has important guiding significance for improving the performance of parallel robot system and promoting the development of parallel robot industry.

\section{REFERENCES}

[1] Gao Qin and Long Yong, chang-lin ma, wen-liang guan Mechanical and electrical integration of liquid system modeling and simulation technology [M]. Beijing: electronic industry press. 2012 .

[2] Sun Jingmin ying-chun liang. Mechanical optimization design (fourth edition) [M]. Beijing: mechanical industry publishing house. 2011.

[3] Su Zijian. Multidisciplinary design optimization of decomposition, synergy and uncertainty study [D]. Wuhan: huazhong university of science and technology. 2008.

[4] li-xun zhang. Mechanical and electrical system modeling and simulation [M]. Harbin: Harbin industrial university press. 2010.

[5] MeiXiaoNing shu-xing Yang. Review the multidisciplinary design optimization of complex systems [J]. Journal of engineering design, 2010, (3) : 173-180.

[6] HeXianM. Intelligent algorithm in multidisciplinary design optimization and the approximate model research [D]. Wuhan: huazhong university of science and technology. 2011.

[7] JiGuoHua, li yan, wen-qiang li, etc. A multidisciplinary design optimization method for complex system [J]. Journal of mechanical design and research of 2011.27 (4) : 6-11.

[8] XiaoMi. Approximate in multidisciplinary design optimization model and solution strategy research [D]. Wuhan: huazhong university of science and technology. 2012.

[9] Xue Lipeng. Tilt rotor machine pneumatic/dynamics multidisciplinary design optimization research [D]. Nanjing: nanjing university of aeronautics and astronautics. 2011.

[10] JiaoLiMing. Multidisciplinary design optimization theory in the application of parallel mechanism [D]. Zhengzhou: zhengzhou university. 2012.

[11] NieYongJun, wiseman. Multidisciplinary design optimization technology and its application study $[\mathrm{J}]$. Mechanical and electrical product development and innovation, 2011.24 (1) : 4 - 6 . 